\title{
OPINIÃO
}

\section{Os dilemas de uma civilização técnica}

Igor Zanoni C. Carneiro Leão*

Este artigo aborda em suas grandes linhas algumas tendências que caracterizaram, no século $\mathrm{XX}$, as sociedades industriais, traçando a seguir paralelos com a formação social brasileira e sua atualidade.

Usaremos como texto-base a coletânea "7 estudos sobre o homem e a técnica", de Georges Friedmann, composta por textos escritos entre os anos finais da II Guerra e meados dos anos 60 quando, por um lado, havia se afirmado uma "sociedade afluente" no mundo capitalista e um "socialismo de caserna" no leste.

O ponto de partida do autor está na transição de sociedades humanas vivendo basicamente em um meio natural e as atividades agrícolas para um meio técnico, representado especificamente pelas máquinas de produção industriais, mas que também se infiltram na agricultura. $\mathrm{O}$ meio técnico também atinge máquinas de transporte, como as estradas de ferro e o automóvel, que se popularizava juntamente com o avião, bem como as máquinas visando as comunicações humanas, como os telégrafos e telefones, e a televisão. O próprio lar, a vida doméstica e a da mulher são penetrados pelos pequenos aparelhos e instrumentos domésticos a preços relativamente ao alcance de todos, transformando as tarefas caseiras.

Mas ao mesmo tempo em que se dá uma mecanização do trabalho, há também uma mecanização do lazer, abarcando o automóvel, o cinema, o rádio, a indústria fonográfica e a televisão. O ponto principal é que esse conjunto de técnicas transformou e transforma profundamente as condições de existência do homem, sua vida do trabalho, do lar, da rua, das diversões: "O homem está subjugado a milhares de solicitações, de excitações, de estimulantes até a pouco desconhecidos. Assim, o conjunto dessas técnicas criadas, instala, aumenta cada dia mais em torno dele o que chamaremos globalmente o meio técnico” (p. 13).

Esse meio técnico complexo criado pela civilização tecnicista transforma os fundamentos psicológicos do antigo meio natural, sua maturação de emoções e de representações em meio a elementos, coisas e seres vivos cujo ritmo os homens tendiam a seguir. Para o autor esse império da civilização tecnicista, sua prodigiosa capacidade de difusão a torna uma civilização totalitária. Nela o ritmo vital pessoal, o ritmo de atividade

\footnotetext{
* Doutor em Economia pela UNICAMP. Professor do Departamento de Economia da Universidade Federal do Paraná (UFPR). Endereço eletrônico: igorza@bol.com.br
} 
física, bem como o de atividade intelectual é alterado, deslocando o homem de sua originariedade. Nesse sentido, o embricamento entre o psicológico, o biológico e o sociológico são alterados na civilização tecnicista. Ao mesmo tempo, o sentido do tempo se altera na vida cotidiana e a sensibilidade e percepção do tempo e do espaço transformam as sensações até mesmo desses elementos centrais da psique.

As maneiras de pensar também variam com as novas maneiras de perceber e de sentir, a lógica do pensamento do cinema e do avião é toda sua e o vocabulário e a sintaxe tornam-se permeáveis ao espírito do novo tempo. O pensamento clássico apoiado na razão e na lógica convivia com o esoterismo e o ocultismo ao passo que o pensamento filosófico atual assentase numa linguagem que se cola ao aparelho científico e em grande parte transborda mesmo aos espíritos mais refratários à ciência.

A sensibilidade muda na medida também em que, por exemplo, a platéia e o palco da arte dramática podem estar separados no tempo e no espaço, como no cinema e na televisão. É problemática a mescla tradicional do espectador ao protagonista que era o fundamento psicológico do drama antigo Esse distanciamento se dá também, em outro exemplo, na medida em que entre o médico e o doente se acumulam técnicas que ocultam ao médico o sentido do doente, o conhecimento de suas necessidades, o tato psíquico.

Essas observações indicam um salto nas sociedades humanas acompanhando um salto econômico, um novo condicionamento psico-sociológico do homem por seu meio. Este contexto altera entre outros exemplos a infância humana, a sua sensibilidade e a sua percepção; o mundo se torna mais difícil de interpretar na medida em que se povoa dessas máquinas unívocas, como o automóvel ou o gramofone. Imagens também se oferecem às crianças nos painéis e na televisão, substituem muitas vezes o texto de seus livros escolares. A criança é envolvida num universo de imagens que a atingem completa e profundamente, deixando o gosto pelos contos antigos e adotando novas formas de diversão.

Também os instintos da nutrição envolvendo não só o que se come, mas a maneira de se comer, os ritmos das refeições, as esperas da fome, as quantidades necessárias ingeridas mudam. Os alimentos em conserva, os bares automáticos, os fast food, são novos dados de uma alimentação tornada excessivamente artificial e condicionada. Outros instintos humanos são afetados, envolvendo os perigos mecânicos, os instintos sexuais e mesmo o que Veblen chamava instinto artesão, característico da antiga indústria e marcado pela criatividade envolvendo a produção por parte do próprio artífice. Isso explica a repugnância de muitos operários da indústria moderna às tarefas parceladas e semi-mecanizadas, reprimindo a 
criatividade aliada ao trabalho. Não apenas a infância, mas o jovem e o adulto são afetados na sua visão da vida e do mundo. A própria verticalidade característica da postura humana e que comanda o desenvolvimento de suas primeiras técnicas, construções e indústrias, é subvertida pela fotografia, o cinema, o avião e as mudanças no sentido do tempo, que tem lugar com as novas formas de abordar o espaço e o tempo na arte e na rapidez de deslocamento do corpo no espaço.

A questão é até que ponto a influência desse novo tempo na psique humana irá prosseguir, de que modo os comportamentos instintivos são chocados, sacudidos, desequilibrados pelo novo meio sem serem substituídos por outros comportamentos seguros, sólidos, dando origem a respostas adequadas. Corre-se o risco de um empobrecimento de riqueza sensitiva e afetiva ou de um intelectualismo sem sensibilidade.

Outra característica importante das sociedades industriais modernas é a relação cidade-campo, ou melhor, a urbanização que não pode ser compreendida sem a noção de um novo meio técnico. As zonas urbanas em desenvolvimento nos Estados Unidos (EUA) ou na Europa, constituíam aglomerações com o predomínio de certos gêneros de vida, submetidos às circunstâncias do meio técnico, ao condicionamento dos indivíduos pelo meio técnico e às reações dos indivíduos a esse meio, às transformações de sua sensibilidade e de sua mentalidade no novo meio.

Aí se encontra um gênero de vida urbana vivido por homens diversamente condicionados pelo meio técnico, marcados, por exemplo, pela assistência ao cinema, a audiência do rádio e as leituras de revistas, configurando um gênero de vida cada vez mais nítido, definível e cientificamente apreensível. O modelo dessa zona urbana é Detroit nos anos 50, onde as principais avenidas se constituíam em artérias quilométricas de cinemas, bares, drug stores, imensas, industrializadas e mecanizadas. Mas inúmeros autores apontavam características semelhantes em diversos outros locais do mundo industrial, particularmente a França, caracterizada por Sauvy por uma "ruralização das cidades" e "urbanização dos campos", mas que, para Friedmann tinha um único sentido: o da tecnificação de todos os espaços humanos.

É interessante notar que essas mesmas tendências se observavam na URSS, onde a vida dos antigos camponeses mudava rapidamente com a tecnificação do país, que o transformou na segunda potência industrial do globo. Essas tendências ficam ainda mais notáveis com a pretensão de Stalin de através da emulação socialista do trabalho estabelecer níveis mais altos de produtividade do trabalhador e preparar a transição do socialismo para o 
comunismo. Também nessas cidades se percebe o mesmo condicionamento pelo habitat, pelo barulho, pela ausência de solidão, pela fadiga dos transportes, pelo efeito das longas migrações de transportes sobre a saúde e o rendimento dos trabalhadores.

Outro aspecto destacado da civilização tecnicista é a liberação de tempo que se separa do tempo de trabalho. Essa separação depende da organização do trabalho e de sua disciplina, da divisão de tarefas, da estrutura das empresas e dos seus exércitos industriais. O tempo livre é separado quase totalmente do tempo de trabalho, ao contrário das sociedades prémaquinistas, onde havia uma porosidade e interpenetração entre tempo de trabalho e tempo livre. A introdução da jornada de oito horas e a redução progressiva da semana de trabalho para cinco dias faz surgir o homem-de-após-trabalho. As férias e o acesso ao lazer de classes com baixos rendimentos, os finais de semana fazem do conjunto das atividades de lazer importante setor da vida social.

Nos países pobres, entretanto, as populações desenraizadas de seu meio natural e ainda não integradas no novo meio da sociedade moderna são expostas aos meios de comunicação de massa e aos apelos do consumo e do lazer mesmo antes de se beneficiar dos elementos primários do bem estar material e da instrução de base. De forma distorcida também aqui as populações são polarizadas pelo atrativo das facilidades, comodidades, fins e meios de evasão que propicia a civilização tecnicista. As pessoas buscam felicidade, mas é difícil ver o lazer em larga escala como contribuição ao desenvolvimento da personalidade e da integridade física ou moral do indivíduo.

Nas civilizações pré-maquinistas, a festa era inconcebível sem a reunião de todos os membros do grupo, e está enredada de ritos, carregada de potência emotiva, manifestada pelo afrouxamento das proibições sociais e por formas próprias de arte popular. Na sociedade moderna as imensas zonas urbanas e suburbanas vêem se perder grande parte do potencial do tempo liberado, como mostra a pobreza das atividades culturais ou as ocupações rotineiras que compõe o lazer. Nesse ponto deve-se fazer uma distinção entre tempo liberado e tempo livre, já que só este último permite a personalidade se exprimir e expandir.

Outro aspecto é que o tempo livre é inseparável das determinações da sociedade industrial, ocorrendo as possibilidades de lazer no interior dos meios de reprodução típicos da civilização tecnicista. As tradições seculares de recreação, de festa, de arte popular desmoronam diante da publicidade, os meios de comunicação de massa, a atração de novas formas de conforto, de deslocamento, o ardor inquieto pelos tipos de evasão real ou imaginária. Cria-se assim uma cultura de massa, onde os bens de consumo culturais 
difundidos pelos meios de comunicação são centrais. Por outro lado, o bomem-de-após-trabalho é com freqüência confinado em uma moradia distante, longe das instituições de lazer, de vida coletiva, política, sindical, cultural. Nesse mesmo momento ele é invadido pelos meios de comunicação de massa que lhe abre um universo imaginário de possíveis. Uma tradição liberal Friedmann vê a possibilidade de passagem do tempo liberado para o tempo livre, o desenvolvimento da educação, estimulando o desenvolvimento da personalidade e atividade criadora.

O resumo dessa reflexão pode ser encontrado no seguinte parágrafo do autor: “Observando, na humanidade do século XX, a aparição de um novo meio, o meio técnico, somos levados ainda mais longe. $O$ emaranhado de influências cotidianas não faz mais que adensar, ameaçando mais e mais os valores humanos do indivíduo, da cultura, em todos os países de indústria evoluída, na Europa como na América. A proliferação diurna e noturna das técnicas, a ronda infernal das necessidades (que elas criam e que, por sua vez, as alimentam), seu ritmo, sua intensidade comandam ações cada vez mais numerosas sobre o indivíduo, sua afetividade, sua mentalidade, seu equilíbrio físico e moral e colocam, para o futuro (ou a primavera) da civilização problemas sempre mais agudos.” (p. 139).

O problema de saber se existe uma alternativa recebe até agora uma resposta negativa, uma vez que a utopia socialista encarnada na URSS, sem criar uma sociedade de consumo de massa, constrangeu o trabalho e o meio social de forma tão opressiva ou mais que no ocidente. Nesse ponto Georges Friedmann parece procurar, sem encontrar, uma alternativa para os dilemas da civilização tecnicista sem, contudo encontrá-la apesar de sua simpatia com o socialismo.

Essas reflexões foram retomadas e aprofundadas tanto pela crítica ao meio técnico quanto pelo estatuto da sociedade de massas, da arte ligada aos meios de comunicação e a própria psicologia do homem moderno por autores como Adorno, Marcuse e outros. Mesmo uma das maiores realizações dessa sociedade, a generalização de um welfare state e uma certa acomodação nas relações entre classes, dando origem ao que Robert Castel chamou a sociedade salarial, cai sob a crítica da desumanização do homem, o trabalho estafante e alienado e a falta de controle sobre a própria vida, além da totemização da técnica e do avanço científico a serviço do meio técnico em todas as suas áreas.

Fazendo algumas reflexões sobre o Brasil, pode-se dizer que os primeiros passos rumo à civilização técnica foram dados a rigor na década de 30 , mas só nos anos 50 , com a industrialização pesada, e depois com a ditadura militar, montou-se no país um panorama 
basicamente urbano com um embrião de consumo de massa e de meios de comunicação também de massa, além de um sistema previdenciário e de bem estar que tendeu lentamente a se generalizar.

Entretanto, esse foi um processo relativamente lento e grande parte da sociedade brasileira ainda estava vivendo no campo sob as técnicas antigas e relações de produção arcaicas do tipo "coronelismo, enxada e voto". A passagem a uma civilização técnica foi possível pela estabilidade do meio técnico no ocidente entre o fim da guerra e os anos 70, abarcando um espaço urbano crescente e depois transformando o próprio meio rural com suas seqüelas das migrações, trabalhadores sem terra e devastação ambiental.

A sociedade brasileira repôs nesse processo o dualismo estrutural de que falava o economista Celso Furtado, convivendo amplas franjas de populações marginais com um núcleo de trabalhadores no centro da indústria mais bem aquinhoados e uma classe média que foi a menina dos olhos da expansão do milagre. Essas populações marginais invadiram os núcleos urbanos sem planejamento e foram submetidos a um processo de desclassificação social em que contavam como massas sujeitas ao império da televisão e dos mass media sem possuírem condições econômicas para um consumo de massa.

As condições de trabalho no campo como na cidade sempre foram muito desiguais, mas em geral marcadas pelo autoritarismo patronal e governamental e as jornadas estafantes de trabalho. O lazer foi sempre instrumentalizado, destacando-se a industrialização do futebol, da música e a presença avassaladora da televisão muito centralizada na Rede Globo.

Nos anos 90 e na atual década o lento crescimento da economia só agravou esse quadro, ampliando-se brutalmente as populações marginais na cidade com suas seqüelas de violência e tráfico de drogas. As cidades brasileiras, mesmo cidades pequenas, são extremamente violentas. O desemprego aumentou, o dualismo se agravou e os migrantes do campo sem espaço na cidade tentam sem projeto claro movimentos como dos Sem Terra. Um problema sério aí é a baixa taxa de crescimento do emprego, do investimento e da renda num contexto de restrição monetária e fiscal do Estado, que diminui os rendimentos da classe média e cria um bolsão de pobreza como o amparado pelo Bolsa Família.

Se este programa ampara os mais pobres, sua intenção original era servir de porta de entrada para outros programas como educação, saúde e de emprego, mas isso se torna inviável sem o dinamismo econômico. Temos hoje 52 milhões de pessoas vivendo desse programa sem perspectiva numa sociedade sem um núcleo duro que sustente com maior vigor o investimento e o consumo. 
Embora os reajustes acima da inflação do salário mínimo tendam também a criar um mercado para os mais pobres, com efeitos dinâmicos sobre setores populares da economia, eles se perdem diante da queda da taxa de investimento e da reclassificação social que se mescla com a crise econômica.

Nesse sentido, as observações de Friedmann são potencializadas pela pobreza, a falta de projeto de nação e um estado de políticas sociais caótico, tudo isso em meio a uma aguda crise política difícil de avaliar pela tendenciosidade dos jornais. Como remontar o país nessas condições numa perspectiva humanista é o nosso desafio.

\section{Referências Bibliográficas}

FRIEDMANN, G. 7 estudos sobre o homem e a técnica, São Paulo: Difusão Européia do Livro, 1966. 
